\title{
Discurso sobre la codicia de las grandes empresas y el declive de la clase media por Bernie Sanders (trad. Jaime Blasco, 2016)
}

\author{
Discurso sobre la codicia de las grandes empresas y \\ el declive de la clase media by Bernie Sanders \\ (trad. Jaime Blasco, 2016)
}

José Abreu

Universidad de Alcalá, Madrid, España

*Autor a quien se dirige la correspondencia: abreucolombri@gmail.com

La trayectoria vital de Bernard (Bernie) Sanders siempre ha estado ligada a la reivindicación social y las políticas progresistas. Nació en Nueva York en 1941, en el seno de una familia identificada con las políticas de Roosevelt. Inició en Vermont su carrera política (1968); consiguió la alcaldía de Burlington (1981) y fue elegido congresista (1990) y senador (2007) por Vermont. Se caracterizó por criticar la teoría económica neoliberal, los procesos de "financiarización" de las estructuras económicas y el intervencionismo militar y el unilateralismo de la administración Bush. En 2016 y 2020, se presentó a las primarias demócratas, obligando al ala derecha de su partido a movilizar recursos para neutralizar su proyecto político, el más progresista y reformador desde los años del New Deal, y mucho más ambicioso que la Great Society.

En el 2015, surgió el primer proyecto de publicación. Era un momento en el que amplios sectores de la prensa afirmaban que el discurso pronunciado por el senador Sanders cinco años atrás era ejemplo de análisis trasnochado y caduco. Ese mismo año decidió publicar un libro con dicho discurso, titulado The Speech: On Corporate Greed and the Decline of Our Middle Class, y determinó que todo lo recaudado en las ventas sería destinado a organizaciones benéficas de Vermont (Nation Books-Perseus Books Group). El libro fue traducido al español por Jaime Blasco y publicado por Malpaso Ediciones (Barcelona, 2016). Se compone de trescientas cuarenta y ocho páginas; la introducción, los agradecimientos y el cuerpo del texto. El apartado principal lleva por título "La economía. (Senado de los Estados Unidos de América, 10 de diciembre de 2010)".

El discurso que se reproduce en el libro intentó soliviantar a la opinión pública, para que presionaran a los legisladores en materia de fiscalidad y de redistribución de la riqueza. En todo su desarrollo, se opone al acuerdo de Obama y los republicanos sobre la ampliación y prolongación de las rebajas fiscales que la administración Bush había aplicado a los multimillonarios. Las palabras del senador Sanders buscaron dar visibilidad a la delicada situación económica de millones de ciudadanos, que apenas podían articular un discurso de descontento, en un ambiente generalizado de discursos triunfalistas, basados en la relación causa-efecto entre el esfuerzo y la recompensa y en el mito de las "oportunidades" para todos.

El principal aporte de esta obra reside en el planteamiento de análisis de la situación económica y social. Su aspecto más valioso, por encima de cualquiera teórico-ideológico, radica en la singularidad de los enfoques temáticos y en la fecha en el que fue pronunciado; ya que, después de un largo periodo de consenso político sobre el modelo económico entre los representantes políticos estadounidenses, las voces críticas contra la desigualdad creciente eran prácticamente inexistentes y se situaban al margen de los discursos oficiales. Sanders (2016) denunció de forma temprana un problema generalizado, frente a resonantes discursos mediáticos de corte neoliberal. Las primeras líneas 
condensan gran parte de su discurso y evidencian su carácter directo y sincero: "[...] creo que todo el mundo sabe que el presidente Obama y los líderes republicanos han alcanzado un acuerdo para sacar adelante un proyecto de ley fiscal muy importante. En mi opinión, este acuerdo perjudica al pueblo americano. Creo que podríamos aspirar a algo mejor [...]" (p. 19). Sanders no tuvo ningún problema en subirse al atril del Senado para criticar abiertamente uno de los principales acuerdos de la administración Obama.

Ampliamente, en esta publicación se desarrollan muchos temas políticos y económicos, y sus repercusiones sociales, que han tenido efectos palmarios durante las últimas décadas. No obstante, el senador Sanders pone el foco sobre unas cuestiones que determinan en gran medida el agotamiento de un modelo económico, la desigualdad social y la falta de oportunidades en el mercado laboral estadounidense: deuda pública creciente, especulación financiera, reducción del gasto social, deslocalización industrial, rebajas fiscales para los grandes acumuladores de activos económicos, etcétera. Se realizan menciones directas a grandes corporaciones y se hacen constantes alusiones a proyectos legislativos demócratas y republicanos.

Una de las cuestiones que más preocupa al senador Sanders guarda relación con el deterioro de las infraestructuras existentes en todo el país y la falta de un plan de creación de nuevos proyectos de construcción a futuro. Entretanto, se aduce que la construcción y el mantenimiento de infraestructuras favorecen el incremento de la productividad y la eficiencia en todos los sectores productivos. Las partidas presupuestarias tienen que aumentar considerablemente para el mantenimiento de la red de infraestructuras en todas las regiones del país, con el fin de garantizar la capacidad de gestión a corto plazo. La exención fiscal no es el camino idóneo para reconducir los desequilibrios. El gobierno federal tiene que considerar las encuestas que hablan de una mayoría social contraria a estos privilegios fiscales.

Respecto a la cobertura social, los legisladores tienen que hacer un esfuerzo en la reforma del sistema sanitario, para garantizar el acceso a un seguro médico a millones de ciudadanos, que en el presente están fuera del sistema de asistencia sanitaria. Algo similar ocurre con la deslocalización industrial, la competitividad empresarial y la justicia salarial. La economía estadounidense no puede competir en los salarios con países como China o Bangladesh. El Departamento del Tesoro y la Reserva Federal tienen que garantizar las necesidades básicas del tejido productivo estadounidense. La especulación financiera tiene que ser controlada y las reparaciones económicas no pueden ir en contra de los intereses de la mayoría social. Se pone como ejemplo el programa de ayuda a los activos tóxicos y sus consecuencias sobre la deuda pública.

En diferentes partes de la publicación se recogen preguntas e interpelaciones de otros senadores, en las que se intenta fijar el debate sobre casos concretos relacionados con la intervención del autor. También se hace referencia a textos legales y proyectos de ley previos para articular la secuencia argumentativa. De la misma manera, se recalca que la desigualdad se encuentra en estado crónico y no para de crecer; además, no es un tema muy común entre los órganos legislativos y entre los representantes políticos; presumiblemente, es un tema muy incómodo desde todos sus planteamientos. Sanders dice: "[...] está bastante claro quién gana y quién pierde con este sistema económico [...] tenemos la distribución de riqueza y de ingresos más desigual del mundo industrializado. No veo que la gente hable de este tema. [...]" (p. 113). Seguidamente, se habla de reconstruir el maltrecho sector industrial a través de estímulos a este tipo de inversión regeneradora y de la eliminación de las políticas comerciales corrosivas para la producción interna.

El senador Sanders hace un esfuerzo constante para apuntalar sus argumentos políticos con elementos narrativos históricos (haciendo referencia a situaciones pasadas clave) y con elementos narrativos periodísticos (estableciendo referentes informativos actuales). A nivel histórico, se mencionan los últimos reductos del progresismo ideológico en el Partido Republicano a comienzos del siglo XX. A nivel de acontecimientos políticos vividos, se enfatizan los errores cometidos por el Partido Demócrata en materia de progresividad fiscal, desregulación económica y estrategia comercial (Bill Clinton y Barack Obama). También se recogen lamentaciones sobre las disfunciones del sistema democrático y la excesiva influencia de los grupos de poder sobre los partidos políticos. Se presenta a la Ley Glass-Steagall como un manual de referencia para reconstruir el país y recuperar la competitividad internacional.

En la parte final del discurso, se menciona a los sectores sociales que viven en situaciones de privilegio y a los ciudadanos que tienen que recurrir al endeudamiento para intentar contrarrestar la pérdida de poder adquisitivo. Se cuestionan las políticas financieras durante la administración Bush y se critica sin 
circunloquios la insolidaridad creciente de la minoría social que concentra una gran parte de la riqueza del país. En este contexto, el senador Sanders dedica unas amables palabras para Thom Hartmann y su libro Rebooting the American Dream, 11 Ways to Rebuild Our Country. La parte final del discurso se despliega sobre la posibilidad de reconsiderar el texto legal y hacer un llamamiento a los sectores implicados.

A nivel periodístico y en contexto de divulgación política, se dijo que este discurso contenía las coordenadas clave para realizar una oposición al modelo económico actual. Del mismo modo, se simplificó todo lo contenido en esta publicación (teórica y conceptualmente) para vincular el movimiento progresista actual con los elementos periféricos del Partido Demócrata. Las interpretaciones situadas más a la derecha del espectro político estadounidense, directamente, hablan de la manifestación blanda de una agenda política comunista y "anti-americana". Grosso modo, el libro ve la luz con el objetivo principal de estimular el pensamiento crítico y la organización cívica entre la ciudadanía estadounidense. Igualmente, se defiende la idea de que la creación de una agenda de reformas de la administración pública supone una necesidad inaplazable. Esto lleva a pensar a muchos analistas políticos de diferentes sensibilidades ideológicas que el senador Sanders sentó las bases de una especie de manifiesto político con este discurso, pronunciado en diciembre del 2010.

\section{Datos editoriales del libro}

Título: Discurso sobre la codicia de las grandes empresas y el declive de la clase media

Autor: Bernie Sanders

Traductor: Jaime Blasco

Lugar y año de publicación: Barcelona, 2016

Casa editora: Malpaso Ediciones, 268 páginas

ISBN: 9788416420872 